\title{
Neuropatia Auditiva: Avaliação Clínica e Abordagem Diagnóstica
}

\section{Auditory Neuropathy: Clinical Evaluation and Diagnostic Approach}

Guilherme Machado de CARVALHO ${ }^{1}$, Beatriz Prista LEÃO², Priscila Zonzini RAMOS ${ }^{1}$, Alexandre Caixeta GUIMARÃES ${ }^{1}$, Arthur Menino CASTILHO ${ }^{1}$, Edi Lúcia SARTORATO3

Acta Med Port 2016 Jun;29(6):353-359 - http://dx.doi.org/10.20344/amp.6942

\section{RESUMO}

Introdução: A neuropatia auditiva é uma condição na qual há alteração na condução neuronal do estímulo sonoro. Este trabalho pretende descrever e caracterizar a casuística de doentes com neuropatia auditiva.

Material e Métodos: Realizámos um estudo transversal, retrospetivo, com descrição de uma série de casos consecutivos. O diagnóstico da neuropatia auditiva foi definido nas seguintes situações: Presença de otoemissões acústicas com potenciais auditivos de tronco encefálico ausente ou anormal e presença do microfonismo coclear independentemente da presença de otoemissões acústicas. Resultados: Foram avaliados 34 doentes com perda auditiva bilateral, $67 \%$ deles do sexo masculino. $O$ aparecimento dos sintomas foi congênito em $80 \%$ dos casos. Na pesquisa das otoemissões acústicas, a resposta foi ausente em $67 \%$ dos doentes. O microfonismo coclear foi detetado em $79 \%$ dos doentes. Antecedentes gestacionais, perinatais ou ambientais relevantes estiveram presentes em $35,3 \%$ dos casos.

Discussão: A literatura médica ainda apresenta grande variabilidade nos achados relacionados com a neuropatia auditiva, tanto na sua etiologia quanto nos dados epidemiológicos.

Conclusão: A neuropatia auditiva apresenta um amplo espectro de alterações que podem resultar em disfunções leves a severas no funcionamento da via auditiva. Na nossa amostra, observámos que $80 \%$ das neuropatias auditivas terão tido origem congênita e/ou apresenta microfonismo coclear, $91 \%$ dos doentes apresenta défice auditivo significativo e $53 \%$ sofrem de surdez severa ou profunda. Palavras-chave: Células Ciliadas Auditivas; Células Ciliadas Auditivas Externas; Células Ciliadas Auditivas Internas; Potenciais Evocados Auditivos do Tronco Encefálico; Neuropatia Auditiva.

\section{ABSTRACT}

Introduction: Auditory neuropathy is a condition in which there is a change in the neuronal transmission of the auditory stimuli. Our objective was to describe the patients' series within the clinical spectrum of auditory neuropathy.

Material and Methods: We designed a transversal, retrospective study, with a description of a consecutive case series. Auditory neuropathy was defined by the presence of acoustic otoemissions plus absent/abnormal auditory brainstem responses with cochlear microphonism.

Results: 34 patients with bilateral hearing loss, 23 males and 11 females, were included in the study. Eighty percent of the cases had congenital onset of hearing loss. Acoustic otoemissions were absent in $67 \%$ of them. Cochlear microfonism was present in $79 \%$ of all cases. Prenatal, perinatal or ambiental factors were present in $35.2 \%$ of the cases.

Discussion: Medical literature shows great variability in findings related to auditory neuropathy, both in its etiology and epidemiological data.

Conclusion: Auditory neuropathy presents a broad spectrum of changes that may result from mild to severe changes in the functioning of the auditory pathway, and in our sample we observed that $80 \%$ of Auditory neuropathy have congenital onset of hearing loss and/ or with cochlear microphonism identified. $91 \%$ of patients experience significant hearing impairment and $53 \%$ suffer from severe or profound deafness.

Keywords: Auditory Neuropathy; Evoked Potentials, Auditory, Brain Stem; Hair Cells, Auditory; Hair Cells, Auditory, Inner; Hair Cells, Auditory, Outer; Mononeuropathies.

\section{INTRODUÇÃO}

A neuropatia auditiva (NA) ou dissincronia auditiva (DA) é um distúrbio auditivo onde a função das células ciliadas externas da cóclea é normal, mas há uma alteração na função das células ciliadas internas e/ou acometimento das fibras do nervo auditivo com dissincronia na condução nervosa do mesmo. ${ }^{1,2}$

Esta patologia auditiva pode acometer indivíduos de qualquer faixa etária, com prevalência variando entre 0,23 e $2 \%$ das crianças, sendo um fator de risco para deficiência auditiva. Acredita-se que por volta de $8 \%$ dos novos casos anuais de perda auditiva diagnosticada em crianças sejam relacionados com a NA. ${ }^{3}$

No Brasil, estão disponíveis poucos dados sobre prevalência e incidência dessa patologia na população geral. Num estudo recente, que avaliou cerca de 2292 indivíduos com perda auditiva, foi encontrada uma prevalência de $1,2 \%$ de doentes com patologia no espectro da neuropatia auditiva. $^{4}$

1. Departamento de Cirurgia do Ouvido, Nariz, Garganta e Cabeça \& Pescoço. Universidade de Campinas. São Paulo. Brasil.

2. Departamento de Medicina. Universidade do Minho. Braga. Portugal.

3. Laboratório de Genética Molecular. Centro de Biologia Molecular e Engenharia Genética. Universidade de Campinas. São Paulo. Brasil.

$\square$ Autor correspondente: Guilherme Machado de Carvalho. guimachadocarvalho@gmail.com

Recebido: 26 de agosto de 2015 - Aceite: 15 de fevereiro de 2016 | Copyright $\odot$ Ordem dos Médicos 2016 
A fisiopatologia da doença é ainda pouco conhecida. Provavelmente a NA não é uma doença única, mas um espectro de patologias que afetam a via auditiva. Em recém-nascidos, diversos fatores como prematuridade, hiperbilirrubinemia, hipercolesterolemia, hipóxia, imaturidade do sistema nervoso central, baixo peso ao nascer, condições idiopáticas, fatores genéticos e ainda outros foram propostos como contribuintes, isoladamente ou em combinação, para o desenvolvimento de NA. . $^{3-6}$

Estão propostas diversas teorias no que diz respeito aos locais de lesão auditiva que cursam com NA, tais como a membrana tectorial, as células ciliadas internas (CCI), as células ciliadas externas (CCE), alterações da liberação de neurotransmissores nas sinapses entre as células ciliadas internas e as fibras dos neurónios do gânglio espiral, alterações na transmissão elétrica das fibras do nervo coclear, problemas axonais diversos ou mesmo relacionados à mielinização do nervo coclear. ${ }^{7}$

A prevalência descrita da NA em doentes pediátricos com hipoacúsia severa ou profunda é de cerca de $13,4 \%{ }^{8}$ De entre os fatores genéticos, muito estudados, estão estabelecidas algumas mutações em genes classicamente descritos e relacionados com a NA, como o OTOF e o PJVAK. ${ }^{4}$ Acredita-se que tais genes possam ser responsáveis por disfunções relacionadas com as $\mathrm{CCl} .^{9}$

Estão já mapeados quatro loci considerados na literatura médica como responsáveis pela NA em doentes não-sindrómicos, de entre os quais: DFNB9 (OTOF) e DFNB59 (PJVK) para casos autossómicos recessivos; AUNA1 (DIA$\mathrm{PH} 3$ ) em casos autossómicos dominantes; 1 AUNX1 em casos ligados ao $X$. De acordo com alguns autores, mutações no gene GJB2 e mutações mitocondriais (12S rRNA) podem também estar relacionadas com a NA. ${ }^{10-15}$ Apesar de estarem descritos casos clássicos de NA em doentes com o diagnóstico genético molecular de homozigotia da mutação 35delG no gene GJB2, a associação entre mutações de GJB2 e NA foi abordada ainda em poucos trabaIhos, não estando estabelecida uma correlação. ${ }^{4,16}$

Na sua evolução, a perda auditiva pode ocorrer em graus variados, frequentemente com alterações na inteligibilidade da fala associadas a alterações nos exames eletrofisiológicos auditivos.

As otoemissões acústicas (OEA) apresentam-se normais com potencial evocado auditivo do tronco encefálico (PEATE)/BERA) normal ou ausente, sendo essa situação considerada como NA clássica. O microfonismo coclear (MC) pode estar presente e os reflexos estapédicos estão normalmente ausentes. ${ }^{17,18}$

Em algumas situações, há outras neuropatias periféricas concomitantes, sendo as mais descritas a síndrome de Guillain-Barré e a doença de Charcot-Marie-Tooth. ${ }^{14,15}$

A reabilitação dos doentes com o diagnóstico de NA, seja com terapia da fala isolada, implante coclear ou com aparelhos auditivos de amplificação sonora individual, deve ser realizada o mais precocemente possível, para uma otimização dos resultados. ${ }^{18}$

O presente estudo tem como objetivo descrever os da- dos epidemiológicos e audiológicos dos doentes pediátricos com diagnóstico de NA, acompanhados no serviço de saúde auditiva de um hospital universitário de referência terciária, evidenciando as características clínicas desses doentes.

\section{MATERIAL E MÉTODOS}

Realizámos um estudo transversal, retrospetivo, com a descrição de uma série de casos consecutivos, através da análise do processo clínico de doentes com diagnóstico de perda auditiva bilateral, com suspeita de patologia no espectro da neuropatia auditiva, acompanhados no serviço de saúde auditiva de um hospital universitário.

As variáveis analisadas foram idade, sexo, data de início da perda auditiva (congénita, na infância, na adolescência ou em adulto), antecedentes gestacionais, perinatais e genéticos, e resultados dos exames eletrofisiológicos: PEATE, emissões otoacústicas transientes e por produto de distorção (OEA), e pesquisa de microfonismo coclear (MC).

Como antecedentes perinatais e gestacionais foram consideradas quaisquer situações descritas nos antecedentes desses doentes como: prematuridade, icterícia, kernicterus, internamento em unidade de cuidados intensivos neonatal, meningite, infeções neonatais graves (como sépsis e pneumonia), síndromes genéticas, doenças neurológicas concomitantes, doenças infeciosas (como rubéola e toxoplasmose), comorbilidades sistémicas clínicas (como hipertensão arterial, diabetes mellitus). Os antecedentes familiares de surdez também foram pesquisados e identificados.

O grupo etário foi definido conforme o início do aparecimento dos sintomas, sendo: congénito (até um ano de vida), infância (entre o primeiro e o $10^{\circ}$ ano de vida), adolescente (entre o $11^{\circ}$ e o $18^{\circ}$ ano de vida) ou adulto (mais do que 18 anos de vida).

O diagnóstico clínico da NA foi estabelecido da seguinte forma: OEA normal e/ou MC com PEATE com respostas ausentes ou anormais, com exames de imagem que excluíssem qualquer alteração anatómica do VIII par craniano.

\section{Amostra}

A amostra utilizada no trabalho foi constituída pelos doentes acompanhados nos últimos três anos (2011 a 2014), no serviço de saúde auditiva de hospital universitário em questão, com o diagnóstico clínico de NA.

Foram incluídos na amostra apenas os doentes que realizaram testes audiológicos e eletrofisiológicos com a nossa equipe de fonoaudiologia (audiologistas e terapeutas de fala), tendo sido utilizados para todos eles os mesmos equipamentos.

\section{Critérios de inclusão}

Os critérios de inclusão foram: perda auditiva neurossensorial; otoscopia normal; ausência de doenças do ouvido médio; exames de imagem (ressonância magnética 
ou tomografia computadorizada) evidenciando a presença do nervo vestibulococlear e excluindo alterações retrococleares; ausência de reflexo acústico; exames audiológicos compatíveis com o espectro clínico da neuropatia auditiva:

a) OEA presentes e PEATE ausente, ou

b) OEA ausentes, PEATE ausente e microfonismo coclear presente, ou

c) OEA ausentes e PEATE ausente com limiares tonais presentes e suspeita clínica de neuropatia auditiva.

\section{Avaliação Audiológica}

Foram realizados os testes audiológicos, incluindo a impedanciometria, audiometria tonal e vocal. Os testes foram realizados com um audiómetro AC30-SD25, calibrado de acordo com a ISO 389/64.

Para as OEA e os PEATE, estes últimos repetidos pelo menos duas vezes, utilizou-se o dispositivo AT-235 (Interacoustics).

As OEA por produtos de distorção foram realizadas nas frequências de 700 a $8.000 \mathrm{~Hz}$, com estímulos de 65 a 55 dBNPS, com razão de frequência de 1,22. As OEA foram consideradas presentes nas situações em que a relação sinal/ruído foi maior do que $6 \mathrm{~dB}$, com reprodutibilidade maior ou igual a $70 \% .^{19}$

O PEATE foi estudado quanto à morfologia, latência (absoluta e interpicos), replicabilidade, amplitude e intervalo entre ondas das ondas I, III e V, sendo o intervalo interpicos I-V considerado normal até ou igual a 4,5 ms. As latências consideradas, das onda I a $\mathrm{V}$ respectivamente, normais foram, aproximadamente, 1.5, 2.5, 3.6, 4.9 e 5.6, estimulada a $100 \mathrm{~dB}$. Para a amplitude foi considerado que quanto maior a intensidade do estímulo maio a amplitude, considerando que habitualmente a amplitude da onda $V$ ser maior que a onda I. A diferença interaural de latências entre os intervalos intepicos foi menor que 0.3 ms. Limiar auditivo foi considerado quando há presença da onda $V$ na menor intensidade. A avaliação eletrofisiológica foi feita nos 12 ms após os estímulos sonoros. ${ }^{19}$

Os testes dos PEATE e do MC foram realizados com fone de inserção. Para os PEATE, o estímulo utilizado foi de 100 dBNA, com frequências abrangidas entre 250 e $8.000 \mathrm{~Hz}$, com duração de 100 microssegundos, e polaridades condensadas e rarefeitas, sendo realizados 2000

Tabela 1 - Distribuição dos doentes segundo o início dos sintomas auditivos e género

\begin{tabular}{llc}
\hline & & $\mathbf{n}$ \\
\hline \multirow{2}{*}{ Gênero } & Masculino & $23(67 \%)$ \\
& Feminino & $11(33 \%)$ \\
& Congênita & $27(80 \%)$ \\
Idade de aparecimento & Infância & $3(9 \%)$ \\
dos sintomas & Adolescência & $4(11 \%)$ \\
& Adulta & $0(0 \%)$ \\
Total & & 34 \\
\hline
\end{tabular}

cliques para cada série, e tendo a pesquisa sido repetida duas vezes em cada intensidade. O teste foi considerado anormal nos casos em que houve ausência de formação de ondas ou se verificou alteração grave da morfologia das mesmas com até 100 dBNA de estímulo. ${ }^{19}$

As principais alterações de morfologia de ondas no PEATE foram relacionadas com deformidade ou mesmo com não formação da onda no período esperado, assim como duração menor ou maior, prolongamentos das ondas, exist6encias de mais de um pico ou a não existência de picos, a não reprodutibilidade das ondas. Isso foi confirmado com estímulos até $100 \mathrm{~dB}$. Os valores normais de latência e amplitude foram adequados em acordo com a idade para a interpretação do PEATE. ${ }^{19}$

O MC foi avaliado nos exames dos PEATE, com o recurso à inversão da polaridade (condensada e rarefeita). Nos casos em que se detetou MC positivo com estímulos de $100 \mathrm{dbNA}$, foi pesquisado o seu limiar eletrofisiológico, de forma decrescente. ${ }^{19}$

A classificação da disfunção auditiva através da audiometria foi feita através da estratificação em disacusia leve, moderada, grave/severa ou profunda. ${ }^{20}$

De acordo com a interpretação profissional dos terapeutas da fala, o desenvolvimento de fala dos doentes avaliados foi classificado, de forma subjetiva, em três categorias (má, razoável ou boa).

\section{Avaliação Genética}

O DNA genómico foi extraído a partir de sangue venoso periférico, de acordo com os protocolos padrão. As mutações foram pesquisadas por sequenciamento direto dos genes avaliados (GJB2). 4,6,9,10

\section{Análise Estatística}

Os dados foram analisados através de uma análise estatística simples, com cálculo das médias, medianas e desvios-padrão.

Para comparar os grupos da amostra, foi utilizado o teste do Qui-quadrado. Devido à reduzida dimensão da amostra em algumas das variáveis analisadas, o teste Exato de Fisher foi também utilizado para verificar a correlação entre os grupos.

O intervalo de confiança foi de $95 \%$, e valor de $p<0,05$ foi considerado significativo.

\section{Aspetos Éticos}

Este estudo foi aprovado pelo Comité de Ética em Pesquisa da instituição (parecer número 396/2006).

Tabela 2 - Achados da avaliação eletrofisiológica

\begin{tabular}{lcc}
\hline \multicolumn{1}{c}{ Avaliação Eletrofisiológica } & Presente & Ausente \\
\hline OEA Transientes & $9(26,5 \%)$ & $25(73,5 \%)$ \\
OEA Produtos de Distorção & $11(33 \%)$ & $23(67 \%)$ \\
Microfonismo Coclear & $27(79 \%)$ & $7(21 \%)$ \\
PEATE & 0 & $34(100 \%)$ \\
\hline
\end{tabular}


Tabela 3 - Grau de desenvolvimento da fala

\begin{tabular}{lc}
\hline \multicolumn{1}{c}{ Qualidade da Fala } & n \\
\hline Má & $21(61,5 \%)$ \\
Razoável & $7(21 \%)$ \\
Boa & $6(17,5 \%)$ \\
\hline
\end{tabular}

\section{RESULTADOS}

Após a criteriosa revisão dos processos clínicos, foram selecionados 49 doentes, porém foram incluídos no estudo apenas 34 doentes. Apesar de termos restringido o tamanho da amostra, a qualidade dos dados desses doentes tornam os resultados mais fidedignos.

A Tabela 1 mostra os principais dados clínicos dos doentes da amostra: $67 \%$ do sexo masculino e $80 \%$ com doença congénita.

Relativamente aos achados da pesquisa bilateral das otoemissões acústicas (Tabela 2), os PEATE foram considerados anormais em todos os doentes que apresentaram ausência de PEATE ou alterações significativas na morfologia das ondas. Em todos os casos com ausência de OEA (transientes ou por produtos de distorção) foi identificado microfonismo coclear, fundamental para a suspeita diagnóstica.

Através da análise da equipe de fonoaudiologia / terapia da fala, a qualidade da fala dos doentes foi classificada em má, razoável ou boa (Tabela 3). Cerca de $62 \%$ dos doentes foram classificados como tendo má qualidade da fala.

Em 12 doentes (35,3\%) foram descritos os antecedentes gestacionais, perinatais e ambientais que estavam presentes, conforme demostrado na Tabela 4.

Os achados da avaliação genética dos doentes são apresentados na Tabela 5. Nenhum dos achados tem relação descrita com a NA. O único caso de homozigotia encontrado foi a mutação $35 \mathrm{delG}$ no gene GJB2, cuja relação com a NA não está ainda estabelecida na literatura. Nenhum dos doentes com alterações genéticas detetadas tinha antecedentes familiares de surdez relatados.

A avaliação audiométrica dos doentes, bem como a relação entre os achados audiométricos e a situação eletrofisiológica em que os doentes foram diagnosticados com NA, está descrita na Tabela 6.

A maioria dos doentes, $53 \%$ dos casos, apresentou disacusia severa/profunda (11 casos severa; sete casos pro-
Tabela 4 - Antecedentes gestacionais, perinatais ou ambientais

\begin{tabular}{ll}
\hline \multicolumn{1}{c}{ Antecedentes } & \multicolumn{1}{c}{$\mathbf{n}$} \\
\hline UTI neonatal & $10(29,4 \%)$ \\
Prematuridade & $6(17,5 \%)$ \\
Antecedentes Familiar de Surdez & $4(11 \%)$ \\
Icterícia & $2(6 \%)$ \\
Kernicterus & $1(3 \%)$ \\
Meningite Neonatal & $1(3 \%)$ \\
Toxoplasmose gestacional & $1(3 \%)$ \\
Pneumonia neonatal & $1(3 \%)$ \\
Síndrome Genética (CHARGE) & $1(3 \%)$ \\
Atrofia Muscular Axial Ascendente & $1(3 \%)$ \\
Comorbilidades Sistémicas & $0(0 \%)$ \\
Ausentes & $22(64,7 \%)$ \\
\hline
\end{tabular}

funda). Em 38\% ( $n=13)$ dos casos objetivou-se disacusia moderada e em $9 \%(n=3)$ disacusia leve.

Não foi estabelecida uma correlação entre o tipo de disacusia e os achados eletrofisiológicos $(p>0,05)$.

\section{DISCUSSÃO}

A neuropatia auditiva é uma condição que tem vindo a ser estudada na última década, por diversos prismas, sendo que atualmente os exames eletrofisiológicos são ferramentas essenciais na avaliação diagnóstica desta condição.

Na nossa casuística, 35,3\% dos doentes apresentaram antecedentes gestacionais, perinatais ou ambientais. Muitos estudos recentes descrevem os possíveis mecanismos causadores da fisiopatologia da NA, principalmente os fatores genéticos. Em cinco casos (14\%) foram detetadas alterações genéticas em genes potencialmente envolvidos na génese da NA, porém, em nenhum dos casos do nosso estudo houve evidência clínica ou laboratorial de uma relação de causa e efeito. ${ }^{19,21}$

Estudos tanto clássicos como recentes defendem que a etiologia da NA está relacionada, em $42 \%$ das vezes com patologias neurológicas hereditárias, em $10 \%$ dos casos com situações diversas (tóxicos, metabólicas, infeciosas,

Tabela 5 - Achados genéticos dos doentes estudados

\begin{tabular}{ccccc} 
Local & Alteração & Frequência $(\mathbf{n})$ & Genótipo & Significado Clínico \\
\hline Exão 2 & p.D43D $(\mathrm{c} .129 \mathrm{C}>\mathrm{T})$ & 1 & Heterozigose & Provavelmente não patogénica \\
Intrão 2 & IVS2 $+28 \mathrm{~T}>\mathrm{G}$ & 1 & Heterozigose & Desconhecido \\
Intrão 4 & IVS5 - 59T > C & 1 & Heterozigose & Desconhecido \\
Intrão 5 & IVS5 + 10A > G & 1 & Heterozigose & Provavelmente não patogénica \\
GJB2 & 35delG / 35delG & 1 & Homogigose & Patogénico (relação com NA?) \\
GJB2 & 35delG / N & 1 & Heterozigose & Provavelmente não patogénica \\
\hline
\end{tabular}


Tabela 6 - Distribuição dos doentes de acordo com os achados audiométricos ${ }^{20}$

\begin{tabular}{lccccc}
\multicolumn{1}{c}{ Disacusia } & OEA + BERA - & OEA - BERA - MC + & OEA + BERA - MC+ & MC + & Total (n) \\
\hline Leve & 3 & 0 & 2 & 0 & 2 \\
Moderada & 6 & 7 & 1 & 7 & $13(38,2 \%)$ \\
Severa & 1 & 10 & 1 & 11 & $11(32,4 \%)$ \\
Profunda & 1 & 6 & $4(11,8 \%)$ & $27(79,4 \%)$ & $34(100 \%)$ \\
Total $(\mathbf{n})$ & $11(32,4 \%)$ & $23(67,6 \%)$ & $70,6 \%)$ \\
\hline
\end{tabular}

...) e que, nos restantes $48 \%$ dos casos, a NA é idiopática. ${ }^{19,21-23}$

Na nossa amostra, quase $40 \%$ dos doentes tinha história gestacional/perinatal ou antecedentes ambientais relevantes, tendo sido os mais prevalentes a prematuridade e a história de internamento $\mathrm{UCI}$ neonatal.

De entre os casos de NA Idiopática, é consensual na literatura que a maioria possa estar relacionada com distúrbios genéticos. Alguns autores consideram inclusivamente que alterações genéticas - sejam elas de origem sindrómica, não-sindrómica ou relacionadas com a herança mitocondrial - serão o principal fator causador da globalidade de patologias do espectro da NA. ${ }^{22}$

Os achados audiométricos de doentes com NA podem variar largamente, havendo desde doentes com limiares considerados normais até situações de disacusia auditiva severa. Assim, não está descrito na literatura um padrão de audiometria para estes doentes, mas antes uma grande variabilidade inter-sujeito. ${ }^{19,21,22}$

O presente estudo demostrou que a maioria dos doentes (53\% dos casos) apresentava disacusia severa ou profunda. Verificou-se a presença de disacusia moderada em $38 \%$ dos casos, e de disacusia leve em $9 \%$. Tal como está descrito na literatura, a amostra estudada apresentou uma grande variabilidade nesses achados, tendo na vasta maioria dos doentes sido objetivado uma perda auditiva significativa.

O diagnóstico de doença congénita foi muito frequente neste estudo, tendo ocorrido em $80 \%$ dos casos. Desses doentes, a maioria foi avaliada no nosso serviço após uma triagem auditiva neonatal com resultados irregulares. Embora a descrição de NA seja feita maioritariamente na população pediátrica, alguns autores defendem que a maioria dos doentes com NA seja diagnosticado em idade adulta. ${ }^{21}$

As OEAs são usadas para avaliar a função das células ciliadas externas e representam fenômenos préneurais relacionados com processos mecânicos da cóclea. A presença de OEAs depende de um sistema auditivo intacto e verificam o funcionamento de parte do Órgão de Corti, representado nessa situação específica pelas células ciliadas internas, e também do sistema eferente auditivo (células ciliadas externas) ${ }^{23}$

Com a progressão da condição patológica, a NA, a totalidade ou quase totalidade das células ciliadas externas são afetadas levando ao desaparecimento do MC e das OEAs. Tal situação pode ocorrer em até 30\% dos doentes com NA, pelo que a ausência de OEA não é um fator de exclusão para o diagnóstico de NA.8,24

O MC é outra forma de verificar o funcionamento e integridade cóclea. Trata-se de um potencial de corrente alternada que aparece durante a estimulação sonora e reflete o movimento da membrana basilar. Esta é uma atividade pré-neural, que acontece antes das sinapses das células ciliadas com o nervo auditivo, ou seja, antes da onda I do PEATE. ${ }^{28}$

De certa forma, o MC avalia também a função das células ciliadas externas e da membrana basilar, o que torna essa avaliação fundamental no diagnóstico da NA e dos seus diagnósticos diferenciais. Como já foi referido, a pesquisa do MC é fundamental na avaliação desses doentes, principalmente na ausência de OEA. . $^{84}$

Em alguns programas de triagem auditiva neonatal, como o do Newborn Hearing Screening Programme, a presença do MC num exame de PEATE incita a investigação ativa de patologias cocleares, como a NA. ${ }^{24}$

Sabe-se que as células ciliadas externas são amplificadoras primárias da cóclea, e que podem auxiliar na modulação da sensibilidade das células ciliadas internas. A disfunção das CCE resulta numa disacusia moderada ( 50 dB). Nesses casos, os doentes necessitam de ambientes de escuta favoráveis (silêncio, sem ruídos competidores) para terem bom desempenho auditivo, além de algum grau de amplificação sonora. ${ }^{25}$

Nas patologias das $\mathrm{CCl}$, geralmente a audiometria cursa com disacusias severas a profundas. A inteligibilidade da fala (discriminação vocal) assim como o desenvolvimento da fala do indivíduo dependerão do grau de perda auditiva, do tempo de aparecimento da patologia (pré- ou pós-lingual) e do tempo de surdez/privação auditiva. A capacidade de discriminar sons e fala no ruído estão frequentemente afetadas, bem como o processamento auditivo. ${ }^{25}$

O MC estava presente em 27 (79\%) dos casos da amostra, sendo que em 23 casos (67\%) a situação encontrada foi OEA-PEATE-MC+, o que demonstra algum grau de integridade coclear, bem como CCEs funcionantes. Importa ressaltar que, também em 23 casos (67\%), as OEA estavam ausentes, o que pode dificultar o diagnóstico de NA para uma equipe médica não especializada. Assim, e indo de encontro ao que está descrito na literatura, nem sempre a situação clássica de OEA+PEATE- é aquela que o doente com suspeita de NA apresenta.

A neuropatia auditiva classicamente cursa com prejuízo 
na discriminação vocal. ${ }^{21-23}$ Em indivíduos com défice auditivo congénito, há um evidente comprometimento do desenvolvimento da fala. Na amostra em estudo, $61,6 \%$ dos doentes com NA apresentava má qualidade da fala e apenas $17,5 \%$ dos doentes apresentavam um desenvolvimento satisfatório desta função, o que poderá estar relacionado com o facto de muitos desses doentes terem sua disfunção auditiva com origem congénita.

Acreditamos no amplo e continuo estudos relacionados com a NA para um melhor entendimento dessa situação clínica. Este manuscrito é parte de um projeto que envolve a NA em sua vertente clínica, genética e relacionada com o implante coclear e outras formas de reabilitação e os estudos relacionados serão estendidos.

Todos os 49 doentes selecionadas estão a ser mapeados geneticamente à procura de novas mutações, bem como de mutações já descritas como relacionadas com a surdez e com a neuropatia auditiva (conexina 26 e 30, mutações no gene OTOF e PJVAC e também um mapeamento completo do DNA desses doentes). Esperamos produzir mais resultados e informações científicas futuras com esses dados. Como a avaliação genética é mais demorada e tem custos mais elevados, principalmente quando orientados na nossa realidade, essa informação ainda não se encontra integralmente disponível para publicação.

A neuropatia auditiva apresenta um amplo espectro de alterações que podem ocasionar desde alterações leves até severas da funcionalidade da via auditiva afectando significativamente o desenvolvimento neurológico do indivíduo, e comprometendo a comunicação oral e o estabelecimento da linguagem.

\section{CONCLUSÃO}

Trata-se de um estudo de casos, logo os resultados apresentados nesse artigo são relacionados a amostra estudada e não devem ser extrapolados à toda população de doentes com neuropatia auditiva. Além do citado, a neuropatia auditiva apresenta uma grande heterogeneidade clínica.

\section{REFERÊNCIAS}

1. Sutton G, Gravel J, Hood LJ, Lightfoot G, Mason S, Sirimanna T, et al. Assessment \& management of auditory neuropathy/auditory dyssynchrony. London: Newborn Hearing Screening Programme; 2008.

2. El-Badry MM, McFadden SL. Evaluation of inner hair cell and nerve fiber loss as sufficiently pathologies underlying auditory neuropathy. Hear Res. 2009;255:84-90.

3. Nikolopoulos TP. Auditory dyssynchrony or auditory neuropathy: Understanding the pathophysiology and exploring methods of treatment. Int J Pediatr Otorhinolaryngol. 2014;78:171-3.

4. Cheng X, Li L, Brashears S, Morlet T, Ng SS, Berlin C, Hood L, Keats B. Connexin 26 variants and auditory neuropathy/dys-synchrony among children in schools for the deaf. Am J Med Genet.2005;139A:13-8.

5. Starr A, Sininger YS, Pratt H. J Basic Clin Physiol Pharmacol. 2000;11:215-30.

6. Berlin Cl, Hood LJ, Morlet T, Wilensky D, Li L, Mattingly KR, et al. Multi-site diagnosis and management of 260 patients with auditory neuropathy/dys-synchrony (auditory neuropathy spectrum disorder). Int J Audiol. 2010;49:30-43.

7. Moser T, Predoehl F, Starr A. Review of hair cell synapse defects in sensorineural hearing impairment. Otol Neurotol. 2013;34:995-1004.

8. Sanyelbhaa $\mathrm{TH}$, Kabel AH, Samy $\mathrm{H}$, Elbadry M. Prevalence of auditory neuropathy (AN) among infants and young children with severe to
$\mathrm{Na}$ amostra estudada nesse artigo, a vasta maioria dos doentes $(80 \%)$ com NA terá desenvolvido doença de origem congénita e/ou apresenta MC. Pudemos também observar, na nossa amostra, que a grande maioria dos doentes, ( $91 \%$ dos casos) apresenta défice auditivo significativo, sendo que cerca de metade dos casos (53\%) se enquadra na classificação de surdez severa ou profunda

A neuropatia auditiva é ainda um desafio, tanto no diagnóstico como na sua abordagem, tratamento e apresenta um amplo espectro de alterações que podem resultar em disfunções leves a severas no funcionamento da via auditiva.

\section{PROTECÇÃO DE PESSOAS E ANIMAIS}

Os autores declaram que os procedimentos seguidos estavam de acordo com os regulamentos estabelecidos pelos responsáveis da Comissão de Investigação Clínica e Ética e de acordo com a Declaração de Helsínquia da Associação Médica Mundial.

\section{CONFIDENCIALIDADE DOS DADOS}

Os autores declaram ter seguido os protocolos do seu centro de trabalho acerca da publicação de dados.

\section{CONFLITOS DE INTERESSE}

Os autores declaram não terem qualquer conflito de interesse relativamente ao presente artigo.

\section{FONTES DE FINANCIAMENTO}

Os autores declaram não ter recebido subsídios ou bolsas para a elaboração do artigo.

Este artigo é parte de um projeto de doutorado, que é financiado pela CAPES (Coordenação de Aperfeiçoamento de Pessoal de Nível Superior, Ministério da Saúde, Brasil). Os autores gostariam de agradecer ao apoio institucional do CNPq (Conselho Nacional de Desenvolvimento Científico e Tecnológico).

profound hearing loss. Int J Pediatr Otorhinolaryngol. 2009;73:937-9.

9. Varga R, Avenarius MR, Kelly PM, Keats BJ, Berlin Cl, Hood LJ, et al. OTOF mutation revealed by genetic analysis of hearing loss families including a potential temperature sensitive auditory neuropathy allele. J Med Genet. 2006;43:76-81.

10. Chaib H, Place C, Salem N, Chardenoux S, Vincent C, Weissenbach J, et al. A gene responsible for a sensorineural nonsyndromic recessive deafness maps to chromosome 2p22-23. Hum Mol Genet. 1996;5:1558.

11. Yasunaga S, Grati M, Cohen-Salmon M, El-Amraoui A, Mustapha M, Salem N, et al. A mutation in OTOF, encoding otoferlin, a FER-1 like protein, causes DFNB9, a nonsyndromic form of deafness. Nat Genet. 1999;21:363-9.

12. Delmaghani S, del Castillo FJ, Michel V, Leibovici M, Aghaie A, Ron U, et al. Mutations in the gene encoding pejvakin, a newly identified protein of the afferent auditory pathway, cause DFNB59 auditory neuropathy. Nat Genet. 2006;38:770-8.

13. Kim TB, Isaacson B, Sivakumaran TA, Starr A, Keats BJB, Lesperance MM. A gene responsible for autosomal dominant auditory neuropathy (AUNA1) maps to 13q14-21. J Med Genet. 2004;41:872-6.

14. Schoen CJ, Emery SB, Thorne MC, Ammana HR, Sliwerska E, Arnett J, et al. Increased activity of Diaphanous homolog 3 (DIAPH3)/diaphanous 
causes hearing defects in human with auditory neuropathy and in Drosophila. Proc Natl Acad Sci USA. 2010;107:13396-401.

15. Wang QJ, Li QZ, Rao SQ, Lee K, Huang XS, Yang WY, et al. AUNX1, a novel locua responsible for $X$ linked recessive auditory and peripheral neuropathy, maps to Xq23-27.3. J Med Genet. 2006;43: e33.

16. Santarelli R, Cama E, Scimemi P, Dal Monte E, Genovese E, Arslan E. Audiological and electrocochleography findings in hearing-impaired children with connexin 26 mutations and otoacoustic emissions. Eur Arch Otorhinolaryngol. 2008; 265: 43-51.

17. Starr A, Picton TW, Sininger Y, Hood LJ, Berlin Cl. Auditory neuropathy. Brain. 1996;119:741-53.

18. Berlin Cl, Hood LJ, Morlet T, Wilensky D, John P, Montgomery E, et al. Absent or elevated middle ear muscle reflexes in the presence of normal otoacoustic emissions: a universal finding in 136 cases of auditory neuropathy/dys-synchrony. J Am Acad Audiol. 2005;16:546-53.

19. Shallop JK, Jin SH, Driscoll CLW, Tibesar RJ. Characteristics of electrically evoked potentials in patients with auditory neurophaty/ auditory dys-synchrony. J Audiology. 2005;43:22-7.
20. Goodman A. Reference zero levels for pure-tone audiometers. ASHA.1965;7:262-73.

21. Penido R, Isaac ML. Prevalence of auditory neuropathy spectrum disorder in an auditory health care service. Braz $\mathrm{J}$ Otorhinolaryngol. 2013;79:429-33.

22. Manchaiah VKC, Zhao F, Danesh AA, Duprey R. genetic basis of auditory neuropathy spectrum disorder (ANSD) Int J Pediatr Otorhinolaryngol. 2011;75:151-8

23. Roush P, Frymark T, Venediktov R, Wang B. Audiologic management of auditory neuropathy spectrum disorder in children:a systematic review of the literature. Am J Audiol. 2011;20:159-70.

24. Rodrigues GRI, Fichino SN, Lewis DR. Presence of cochlear microphonics in click-ABR: differential diagnosis between auditory neuropathy spectrum disorder and steeply sloping cochlear hearing loss in children. Rev CEFAC. 2010;12:1077-83.

25. Rapin I, Gravel J. Auditory neuropathy: physiologic and pathologic evidence calls for more diagnostic specificity. Int $\mathrm{J}$ Pediatr Otorhinolaryngol. 2003;67:707-28. 